\title{
I hovedet på en læser
}

\section{Et fors $\emptyset g$ på at forstå lydbogslæseren}

\author{
Reading well is one of the great pleasures that solitude can \\ afford you, because it is, at least in my experience, the most \\ healing of pleasures. It returns you to otherness, whether in \\ yourself or in friends, or in those who may become friends. \\ Harold Bloom How to Read and Why (2000) \\ Audio is one of the most intimate forms of media because you \\ are constantly building your own images of the story in your \\ mind and you're creating your own production. \\ Emma Rodero i "Inside the podcast brain: Why do Audio \\ Stories Captivitate? The emotional appeal of listening",
} Atlantic, 16.4. 2015.

De to indledende citater belyser forskellige aspekter af, hvordan to forskellige medier (bogen, lydmediet) kan forbindes med nærhed og intimitet, samt hvordan henholdsvis læsning og lytning på forskellig vis åbner for aktiv medskabelse og fantasi. Det er imidlertid slående, hvordan læsningens eller lytningens sociale eller kollektive aspekter forsvinder i citaterne. Er der virkelig tale om hovedsageligt individuelle aktiviteter? Eller har læsere - uanset om de lytter eller læser - behov for at komme i kontakt med andre mennesker på forskellig vis for at afprøve deres fortolkning af et litterært værk og diskutere det, de lige har lyttet til? Og hvilken rolle spiller egentlig i denne sammenhæng det format, hvorigennem vi tilgår et litterært værk?

Det første citat stammer fra Harold Blooms How to Read and Why, hvor Bloom fortolker og går i dialog med litterære værker i forskellige genrer som drama, noveller, romaner og lyrik. De skønlitterære værker og forfatterskaber, som han diskuterer, er velkendte i litteraturhistoriske sammenhænge (som for eksempel Dickens, Nabokov og Austen), og Bloom præsenterer tekstuddrag og nærlæsninger, argumenterer for fortolkninger og peger på de litterære værkers fortjenester. For Bloom er læsning at betragte som den største fornøjelse, ensomhed (solitude) kan skænke, og $i$ en anden passage af How to Read and Why betoner han betydningen af at læse litteratur ved at fremhæve hensynet til individet på følgende vis: "The pleasures of 
reading indeed are selfish rather than social. You cannot directly improve anyone else's life by reading better or more deeply" (Bloom 2000, 22).

Både $i$ et historisk og $i$ et nutidigt perspektiv kan forestillingen om litteraturlæsning som en primært 'selvisk handling' ("selfish rather than social") imidlertid problematiseres og nuanceres. I litteraturhistorien findes der flere eksempler på litteraturlæsningens kollektive potentiale i form af højtlæsningskulturer, som dukker op i løbet af historien såvel som i samtiden. Eksempelvis kan højtlæsningens betydning kobles til både forfatterbegrebets udvikling og til litteraturformidling for børn og unge, litterære salonkulturer, bogklubber og højtlæsning i hjemmet eller inden for biblioteks- eller uddannelsesverdenen. ${ }^{{ }^{1}}$ At læse stille på egen hånd er på flere måder et modernistisk fænomen og kan også forbindes med den måde, litteraturen distribueres på og forfatterens udvikling som individuel aktør på bogmarkedet i det 20. århundrede. ${ }^{2}$ Samtidig kan den individuelle læsning, som sker stille og i ensomhed, ifølge Elizabeth Long betragtes som et "hegemonisk billede", som tilslører, hvordan læsning faktisk er en socialt indrammet aktivitet (Long 1993, 192).

Forestillingen om litteraturlæsningen som enten en social eller en individuel aktivitet kan yderligere problematiseres i det digitale medielandskab i lyset af de forskellige typer af digitale platforme, som giver læseren adgang til en mængde litterære tekster og tillader ham eller hende at dele sine egne tolkninger af disse tekster med andre brugere. De tilgængelige platforme for sådanne diskussioner har også forskellige karaktertræk, alt fra at være hjemmesider særligt rettet imod læseranmeldelser (som for eksempel goodreads.com) til at være skabt af grupper af mennesker, som er interesserede $i$ at diskutere litteratur inden for rammerne af de allerede eksisterende sociale medie-platforme (som for eksempel når grupper af litteraturinteresserede samles på Facebook). De digitale medier har også gjort det muligt at dele egne litterære tekster på blogs, mikroblogs eller billedblogs, og dér anvende brugerskabte markeringer såsom hashtags til at markere værket som en del af den litterære kultur (Pennlert 2019). Endelig har den digitale teknologi medført flere forskellige typer af niche- og print-on-demand forlag eller digital litteratur, som på forskellig vis er skrevet til at blive læst på en skærm (Hayles, 2008). I Social Reading: Platforms, Applications, Clouds and Tags (2013) beskriver Cordón-García m.fl., hvordan læsningen befinder sig i konstant forandring i samklang med den samfundsmæssige og teknologiske udvikling. Samtidens læsere er, ifølge forfatterne, kendetegnet ved, at de bliver mere sociale og samarbejdsvillige samtidig med, at nye teknologier potentielt medfører, at de udvikler nye kompetencer. Cordón-García m.fl. skriver følgende: "The shift is fostered by a new mentality which is more sociable and cooperative and by new technologies which support it with cutting-edge developments that enable new intellectual and informational competences to emerge" (Cordón García m.fl., 2.).

Parallelt med at læseren får adgang til nye digitale redskaber, som gør det muligt at dele læseoplevelser, har den digitale teknologi også medført, at nye litterære formater og distributionsmodeller har etableret sig på bogmarkedet. En svensk rapport, som kom for nogle år siden, konstaterede, at 4 ud af 10 solgte bøger blev solgt via digitale abonnementstjenester; et tal som man forventer vil være forøget i 2020 
(Wikberg 2019; Hanner m.fl. 2019). I et historisk perspektiv er det ikke så mærkeligt, at nye teknologier åbner for nye måder at producere og konsumere litteratur på. ${ }^{3}$ Særligt lydbogen er i de seneste år blevet et væsentligt format for skønlitteratur, og ikke sjældent anvendes betegnelsen "lydbogsboom" for at beskrive den aktuelle udvikling (Pennlert 2019).

Ifølge Matthew Rubery er lydbogslæsning en af de eneste former for læsning, som faktisk øges i dag (Rubery, 1). I forlængelse af Rubery sætter denne artikel fokus på lydbogsbrug som en form for læsning, der kan blive udgangspunkt for en nærmere diskussion af, hvad der sker med læsningens sociale og individuelle aspekter i en digital tid. At lydbogsbrug betragtes som læsning indebærer også, at andre aspekter end den verbale tekst kan regnes som betydningsfulde i læsningen og tolkningen af et skønlitterært værk, som for eksempel oplæserens tonalitet, rytme eller tilsatte lydeffekter.

Disse aspekter afspejler, hvordan lydbogen er forbundet med en anden betydningsfuld medieudvikling i samtiden, nemlig en øget produktion og brug af podcasts. I en artikel fra The Atlantic, som også blev citeret i indledningen til denne artikel, peger Paul Zak, chef for centret for neuroøkonomiske studier på Cleremont Graduate University, på ligheder og forskelle mellem podcasts og lydbøger. Zak diskuterer, hvordan fortællinger, som formidles i lydbogsformat, med fordel kan være karakterdrevne men også indeholde noget, som lytteren kan sympatisere med, såsom en personlig fortælling. Han henviser til et studie fra University of Waterloo, som konstaterer, at mennesker, som lytter til en bestemt tekstpassage i lydbogsformat, husker mindre og er mere tilbøjelige til at "dagdrømme" end de, som læser samme tekst i trykt format, højt eller stille for sig selv. Grænserne mellem podcasts og lydbøger er, ifølge Zak, på vej til at opløses,

4 But anyone who has gotten hooked on a podcast knows that audio can be much more than just narration. [...] Audiobook producers are catching on, and have started rolling out new types of "audio entertainment". (Wen, Atlantic, 16.4. 2015.)

I samme artikel interviewes også Emma Rodero, professor i kommunikationsstudier ved universitetet i Barcelona. Rodero påpeger, at selvom både læsning af trykte tekster og lytning gør det muligt for læseren at udvikle 'egne mentale billeder' af scenerne og karaktererne, har lydbogsmediet den fordel, at hjernen tvinges til at være mere aktiv i forhold til fortællingens tempo og rytme (ibid.).

Lydbogslæsning kan altså forbindes med de forestillinger om den aktive og medskabende læser, som vi også så ovenfor i de indledende citater. Men på hvilken måde kan lydbogen som format og lydbogslæseren forstås i forhold til de forestillinger om læseren som social, der dominerer i den digitale kultur? Eller er lydbogslæsning snarere primært at betragte som noget, man gør alene - og som således fremmer læsningen som individuel praksis? Formålet med denne artikel er først og fremmest at undersøge, hvordan lydbogen og lydbogslæseren kan tolkes og forstås ud fra begrebsparret social og individuel læsning. Disse to modpoler bliver konkrete i forhold til lydbogen: lydbogen er ofte blevet diskuteret som en del af en større tendens, hvor kulturforbrug først og fremmest sker gennem lyd. Derfor bliver lydbogen 
ofte forbundet med en $\varnothing$ get individualisering, idet det bliver muligt for individet at isolere sig i en egen 'lydboble', til trods for at han eller hun befinder sig blandt andre (Bull). I lyset af et øget fokus på social læsning generelt i den digitale litterære kultur, findes der imidlertid anledning til nærmere at unders $\varnothing$ ge, i hvilken udstrækning lydbogsanvendelse også kan betragtes som en social aktivitet, samt hvordan de kollektive dimensioner af lydbogslæsning kommer til udtryk. At kortlægge og fortolke lydbogslæserens sociale spor indebærer muligvis også en fremkommelig vej fremad for at udvikle et vokabular omkring lydbogens forhold til og berøringspunkter med den trykte bog (Rubery, 1).

Artiklen er struktureret på følgende måde: først gives en kortfattet gennemgang af og nedslag i forskning, som diskuterer læseren som én, der faktisk gør noget med teksten, det vil sige forholder sig aktiv i mødet med en specifik litterær tekst. Denne aktive rolle hos en læser eller medieforbruger kan forbindes med de to citater af Bloom og Rodero og kan spores langt tilbage i litteraturhistorien, men er samtidig tæt knyttet til aktuelle forandringer i den digitale kultur. Således er det vigtigt at gøre opmærksom på, hvordan det digitale medielandskab potentielt forandrer, hvordan og hvad vi læser, samt åbner for nye sociale aspekter i den samtidige litterære kultur. Jeg forbinder disse teoretiske diskussioner med lydbogens aktuelle renæssance som format for skønlitteratur: delvist med fokus på lydbogens hurtige etablering på bogmarkedet, men også med fokus på i hvilken grad forskellige former for læsere og læsninger forbindes med lydbogen som sådan.

Efter disse dybdeboringer i det teoretiske ræsonnement vil jeg analysere, hvordan lydbogslæserne selv diskuterer deres læsninger, dels ved at undersøge anvendelsen af anmeldelsesfunktionen på Storytel, dels ved at se på diskussionerne i en bestemt gruppe på Facebook, hvor lydbogslæsere mødes og deler deres lydbogsoplevelser, kommer med bogtips til hinanden eller på anden vis kommunikerer socialt omkring lydbogen. At artiklen især sætter fokus på dette materiale, skyldes for det første, at disse tekstuelle 'spor’ efter lydbogslæserne giver et indblik i, hvad der sker 'i hovedet' på læserne, nemlig i form af den skriftlige respons og de reaktioner, de giver udtryk for, særligt inden for rammerne af de store streamingtjenester for lydbøger i Sverige og Danmark. For det andet bliver jeg, ved at undersøge receptionen og diskussionen hos disse læsere, også i stand til at studere nærmere, hvordan lydbogen som format bliver fremhævet eller kritiseret i brugernes egne diskussioner. Dermed bliver det muligt at få indblik i, hvilke typer af læsning, lydbogsbrugerne benytter sig af. Selvom digitalt materiale medfører bestemte metodologiske overvejelser - som jeg straks vil vende tilbage til - er denne type af studier tidligere blevet gennemført for at få indblik i, hvordan læsere kommunikerer omkring specifikke litterære værker. ${ }^{4}$ Mit bidrag vil her være specifikt at fokusere på kommunikation omkring lydbøger.

\section{Læseren i samtiden - nogle teoretiske perspektiver}

Som påpeget ovenfor findes der flere historiske spor at følge i den teoretiske diskussion om læseren som en aktiv agent og læsning som social aktivitet. For eksempel kan den sociale dimension af lydbogslæsning forbindes med højtlæsning som meto- 
de for litteraturformidling og fremmelse af læsning, eller med etableringen af litterære salonkulturer i det 17. og 18. århundrede. Den sociale dimension har desuden været i fokus inden for receptionsteorien og litteratursociologien: således forbindes studier inden for disse felter ofte med et større fokus på, hvordan litteraturen anvendes, cirkulerer og fortolkes i grupper eller af individuelle læsere. ${ }^{5}$

Fælles for receptionsteoretikere som for eksempel Stanley Fish, Jonathan Culler og Louise Rosenblatt er, at de alle diskuterer læserens fortolkningsaktiviteter og samspillet mellem tekst og læser. Der findes dog også betydningsfulde forskelle mellem dem: mens Fish i sin Is There a Text in This Class? (1980) fokuserer på, hvordan grupper af læsere udvikler særlige fortolkningsegenskaber i forhold til og sammen med andre, diskuterer Rosenblatt i Literature as Exploration (1968) hovedsageligt, hvordan læseren kan benytte sig af forskellige former for læsning i fortolkningsarbejdet. Selvom hendes gennemgang kan siges at være skematisk og skitseret, får hendes grundantagelser om, at læseren er medskaber af teksten, og at litteraturfortolkning sker ved at læseren på forskellig vis forholder sig aktivt til en given tekst, fornyet betydning inden for nutidens diskussioner om læserens rolle i det digitale medielandskab; et emne jeg straks vender tilbage til.

I de seneste år ses også en ny interesse i læsernes forskellige strategier, repræsenteret af for eksempel Rita Felskis Uses of Literature (2008). Allerede titlen afslører, at Felski er interesseret $i$ at undersøge, hvordan litteratur anvendes, og hvordan almindelige læsere på forskellig vis kan forholde sig til en litterær tekst. Felski identificerer i sin bog fire forskellige "modes of textual engagement", som, hun mener, har betydning i læserens møde med en tekst. Disse fire er genkendelse (recognition), fortryllelse (enchantment), viden (knowledge) og chok. For Felski er det altså centralt, hvor en tekst anvendes (use), men hun pointerer også, at denne anvendelse ikke altid er strategisk og meningsfuld og ikke altid er rationel (Felski, 7). Hun peger på, at læseren tager aktivt stilling og på forskellig vis anvender litteraturen, når han eller hun møder en skønlitterær tekst.

\section{Anvendelse af lydbøger - lyden, livsstilen og læseren}

Selvom Felskis ræsonnement først og fremmest tager udgangspunkt i læsning af trykte tekster og omhandler læsningen af trykte bøger, er det også muligt at forbinde ræsonnementet til, hvordan lydbogen anvendes af sine læsere. I de seneste år har lydbøger etableret sig på bogmarkedet, og branchen har udviklet abonnementsbaserede forretningsmodeller, hvor læseren, gennem en app til mobiltelefonen og for en månedlig pris, får adgang til et større katalog af lydbøger. I den generelle diskussion af lydbøger findes flere centrale temaer, som forbinder sig til, hvordan mennesker vælger at anvende litteratur i samtiden, og man har her især betonet lydbogslæserens opførsel. ${ }^{6}$

Lydbogen kan samtidig forbindes til en bredere udvikling i mediekulturen, hvor forbrugerens magt og individuelle præferencer bliver praktiseret. På denne måde konkurrerer lydbogen ikke udelukkende med læsning af den trykte skønlitteratur, men befinder sig også i en opmærksomhedsøkonomi, hvor flere formater konkurrerer om forbrugernes gunst og loyalitet. Det er således tydeligt, at lydbogsproducen- 
ter som Storytel kigger ud over de traditionelle markeder for litteratur og i stedet peger på streamingplatforme for tv-serier og film, som Netflix og HBO, som deres hovedkonkurrenter.7

I forlængelse af ovenfornævnte fokus på anvendelsen af lydbøger er lydbøger ofte i kulturdebatten blevet diskuteret som en form for skønlitterær læsning, som kan pågå samtidig med, at brugeren gør andre ting, som for eksempel træner, gør rent eller pendler (Pennlert 2019). I denne samtidsbeskrivelse kan lydbogslæsningen siges at passe ind i litteraturlæserens "livspuslespil" (ibid), idet den samtidige læser beskrives som én, der altid befinder sig i bevægelse: Lydbogen fremmer således, hvad der af og til betegnes som mobil læsning. ${ }^{8}$ Her er det altså den individuelle læsers litteraturbrug, samt de mediespecifikke egenskaber, som er forbundet med det medium (mobiltelefonen), hvorigennem læseren får adgang til lydbogen, som betones.

Billedet af at lydbogslæsning udelukkende skulle være forbundet med en moderne læsers individuelle og mobile livsstil kan imidlertid nuanceres og problematiseres. Rapporten "Ljudboken: Hur den digitala logiken påverkar marknaden, konsumtionen och framtiden" (2019) bygger delvis på et speciale, der undersøger holdninger og intentioner hos lydbogslæsere, som anvender digitale streamingtjenester, i et studie med i alt 958 respondenter. Et spørgeskema blev distribueret digitalt og postet på relevante Facebook-sider, som var forbundet med lydbøger eller bøger. ${ }^{9}$ Resultatet af denne undersøgelse blev diskuteret i rapporten som udtryk for, hvorfor folk vælger lydbogsformatet: den konkluderede, at motivet var "vores grundlæggende behov for menneskeligt selskab" (29) samt at "en højtlæsende menneskelig stemme giver lytteren en tryghedsfølelse og får vedkommende til at føle sig mindre ensom" (35). Forfatterne til rapporten beskriver dette resultat, at lydbogsbrug kan forbindes til sociale motiver, og at læserens tilvalg af lydbogen som format for litteraturbrug således har en social dimension, som højst overraskende.

Denne sociale dimension kan forbindes med de intime aspekter, som generelt kendetegner højtlæsning, og som angiveligt overføres til lydbogsformatet. Rapporten konstaterede, at behovet for menneskeligt selskab, eller den tryghedsfølelse, som lydbogsbrug medfører, kan "sammenlignes med den følelse et barn får, når deres forældre eller en anden voksen læser for det" (35). Det, som rapporten derimod ikke behandler, er, hvad der sker, når denne interaktion bliver medieret (jf. Castells), og hvorvidt der findes nogle mediespecifikke egenskaber ved lydmedier, som er særligt egnede til at etablere eller fremme sociale relationer eller oplevelsen af intimitet. I artiklen "Radio: The Intimate Medium" (1998) konstaterer Lou Orfanella for eksempel, at radio er intimitetens medium, ved at forklare følgende: "There is an intimacy: a one-to-one connection that no other media can match" (Orfanella, 53). I slutningen af sin artikel konkluderer Orfanella ydermere: "Radio has the power to individualize its presentation within the mind of every listener" (55). Hvorvidt denne oplevelse af intimitet, som her altså specifikt forbindes med radio-mediet, også kan overføres til andre former for lydfortællinger, som f.eks. lydbøger, står stadig tilbage at undersøge, selvom resultaterne af ovenfor nævnte rapport kunne tyde på at det, i alt fald til en vis grad, er tilfældet. 


\section{Den digitale læsning, hyperlæsning og grænseflader}

Siden årtusindskiftet har forskningen på forskellig vis behandlet spørgsmål, dels om hvad det indebærer at læse digitalt (gennem skærme eller andre digitale redskaber), dels om hvordan digital teknologi påvirker eller opbygger relationer mellem læsere

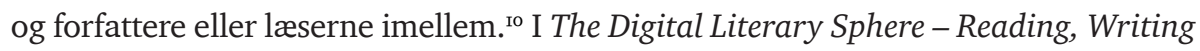
and Selling Books in the Internet Era (2018) stiller Simone Murray således et retorisk spørgsmål om, hvordan den digitale kommunikationsteknologi påvirker den samtidige litterære kultur (Murray, 1). Teoretikere som N. Katherine Hayles og Naomi Baron sætter specifikt fokus på læsning i denne sammenhæng, idet de undersøger skærmens og de digitale mediers betydning for, hvordan og hvad vi læser (Hayles 2014; Baron 2015). I How We Think - Digital Media and Contemporary Technogenesis (2012) demonstrerer Hayles for eksempel, hvordan digitale miljøer på forskellig vis medfører, at en ny type opmærksomhed, hyperopmærksomhed (hyper-attention) vinder frem, hvilket igen påvirker, hvordan og hvad vi læser. Hun skriver:

(f) In

In contemporary digital environments, the information explosion of the web has again made an exponentially greater number of texts available, dwarfing the previous amount of print materials by several orders of magnitude. In digital environments, hyper reading has become a necessity. It enables a reader quickly to construct landscapes of associated research fields and subfields; it shows ranges of possibilities; it identifies texts and passages most relevant to a given query; and it easily juxtaposes many different texts and passages. (Hayles 2012, 62)

Hayles' begreb om hyperlæsning indfanger dog ikke de kollektive eller sociale aspekter af læsning i en digital tid, og således heller ikke, hvad der sker, når mennesker deler viden, erfaringer eller fortolkninger med hinanden på digitale platforme. Disse aspekter bliver i stedet belyst af medieteoretikere som Henry Jenkins, der i Convergence Culture (2006) beskriver, hvordan kulturforbrug i den digital tidsalder er blevet en kollektiv proces, som kendetegnes af social deling af viden i et særligt område (Jenkins).

Begreber, som stammer fra den digitale teknologi, er endog begyndt at blive anvendt som analytiske termer til at forstå, hvordan mennesker interagerer med teknik, eller på hvilken måde digitale miljøer kan fremme eller forstærke bestemte former for opførsel. Disse nye begreber, som stammer fra computerverdenen og siden er blevet introduceret og anvendt inden for humanistisk forskning, kan ses som et resultat af det voksende tværvidenskabelige felt digital humaniora. De kan dog også betragtes som et naturligt skridt i en tid, hvor læsning og skønlitteratur præsenteres i forskellige formater samtidigt. ${ }^{\text {II I }}$ artiklen "Grensesnittens estetik" applicerer Anders Skare Malvik begrebet interfaces eller grænseflader (gränsnitt) på skønlitterære tekster og læsning og konstaterer, at det er muligt ved hjælp af interfacet som analytisk begreb at få yderligere forståelse for forholdet mellem (samtids)æstetik og mediekultur. I Malviks definition kan interfacet altså ses som en potentiel kontaktflade mellem tekst og læser. Men begrebet har også sociale implikationer, ifølge Malvik, og det sociale interface kan således beskrives som "den erfaringsmæssige relation mellem et betragtende/læsende subjekt og et kunstværk" (Malvik 2014, 44). 


\section{Læsningens sociale dimensioner}

I kraft af den digitale medieudvikling har læserne fået adgang til flere forskellige platforme, hvor de kan komme i kontakt med en litterær tekst eller læse andres fortolkninger af litteratur. Samtidig har disse nye muligheder også medført, at læserne på en mere direkte måde kan indgå i sociale sammenhænge, hvor de møder andre mennesker på digitale platforme og deler deres læseoplevelse.

Ved at sætte et begreb som interfaces ved siden af et litteratursociologisk fokus på relationen mellem litteratur, samfund og teknologi er det muligt at få indblik i, hvordan begge felter er præget af grundantagelser om, hvordan læseren kan betragtes som en aktiv agent. En teoretiker, som holder fast i en lignende antagelse og redegør for læserens sociale kompetencer, er Elizabeth Long. I sit kapitel "Textual Interpretation as a Collective Action" i The Ethnography of Reading konstaterer Long, at læsning er en del af en social infrastruktur (Long 1993, 191). Denne sociale infrastruktur beskriver hun på følgende vis:

Uf By the "social infrastructure of reading" I mean two things. Foundationally, that reading must be taught, and that socialization into reading always takes place within specific social relationships. (...) Even beyond formal socialization into reading, the habit of reading is profoundly social. (...) Reading thus requires, in the second sense of the term, an infrastructure, a social base, in much the same way as modern transportation requires a physical infrastructure of highways, aiports and fuel supplies. (ibid.)

I denne artikels sammenhæng er det især relevant, hvordan Long forbinder læsningens infrastruktur med sociale såvel som teknologiske perspektiver. For at følge Longs ræsonnement er læsning altså at betragte som en social aktivitet på flere niveauer. Ifølge hende er læsning både en socialiserende aktivitet i sig selv og noget, som altid sker i forbindelse med, at læseren befinder sig i (forskellige former for) sociale sammenhænge.

Specifikt i forhold til lydbogslæseren, så kan han eller hun vælge at efterlade sig spor og således på forskellig vis give udtryk for sin relation til en specifik litterær tekst - for eksempel ved at beskrive sin oplevelse af teksten i en anmeldelse, som publiceres digitalt. På denne måde kan digital teknologi og sociale medier synliggøre læsningens sociale aspekter på flere niveauer, men også gøre det muligt at undersøge, hvordan et specifikt litterært værk modtages og opleves af en individuel læser. ${ }^{12}$

\section{At følge lydbogslæserens spor: relationer og kommunikation blandt lydbogsbrugere}

Selvom streamingtjenester for lydbøger ikke hovedsageligt kan beskrives som sociale medier eller digitale mødesteder, tilbydes læserne visse muligheder for at interagere med hinanden gennem en række funktioner. På Storytel kan læseren for eksempel poste sine reaktioner på et bestemt litterært værk ved at benytte det tilgængelige bedømmelsessystem på tjenesten, hvor man uddeler stjerner. Én stjerne markerer en lav bedømmelse, og fem stjerner er den højeste bedømmelse. Lignende 
markeringssystemer anvendes på andre digitale anmeldelsessites, som goodreads.com eller kritiker.se. Stjernesystemet på Storytel kan ses som en blanding af anvendergenererede markeringer og digitale paratekster. ${ }^{13}$

I appen findes visse paratekster, som tydeligt remedierer den trykte bogs mediespecifikke egenskaber eller forholder sig til sammenhænge, som historisk er forbundet med bogmediet, mens andre er mere digitalt prægede. Under "Kategorier" præsenteres læseren for et par velkendte genre-inddelinger, som "krimier", "spændingsromaner" og "lyrik \& dramatik", men her findes også andre kategorier, som kan siges at være specifikke for lydbogens digitale format, som eksempelvis "Snabblyssnat" (hurtiglyttet o.a.) eller "Kun på Storytel". Mens "Snablyssnat"-kategorien afspejler, hvordan mobilskærmen og de digitale medier fremmer tekster i det korte format, sådan som bl.a. Naomi Baron fremhæver (Baron 2015), er den anden kategori, "Kun på Storytel", i stedet at betragte som en paratekst, der betoner eksklusivitet og præsenterer et indhold, som er afgrænset og specifikt produceret for Storytel. Denne trend, at abonnementsbaserede streamingtjenester i højere grad end tidligere producerer eget indhold, findes ikke blot inden for det litterære felt, men også inden for andre mediekulturer, som for eksempel på streamingtjenester som HBO og Netflix.

I appen findes der også kategorier, som lægger op til, at læserne skal dele læseoplevelser og komme med litteraturtips til hinanden. Under kategorien "bogtips" findes boganbefalinger, som er tilpasset den enkelte bruger, og som er resultatet af en kombination af digitale udvalgsmekanismer og historisk farvede toplistefunktioner. Her kan læseren vælge at sortere boglisten efter kategorier som "Mest læst i den seneste uge" eller "Bedste bedømmelser øverst". I den sidstnævnte kategori præsenteres litterære værker, som er bedømt af andre lyttere, i en liste, hvor bedste bedømmelse genererer størst synlighed og en topplacering på listen. Retningslinjerne for at foretage disse bedømmelser er beskrevet nærmere i Storytels hjælpecenter, "Hvordan du anvender Storytel - funktioner i appen." Her beskrives den almindelige anmeldelsesfunktion, men også den funktion, som kaldes bedømmelse, hvor læseren som nævnt kan uddele stjerner. Storytel skriver følgende omkring anmeldelse og bedømmelse: "Hvis du vælger at bedømme bogen, får du også alternativet at skrive en anmeldelse af bogen, hvor du kan dele dine tanker og følelser" (support.storytel.com). Men hvad er det egentlig for tanker, som formidles og deles? Og hvilke følelser er det, som læserne fremhæver som betydningsfulde i forbindelse med fortolkningen af en lydbog?

\section{Materiale og metode}

I kategorien "Populære titler lige nu!" på Storytel findes en række eksempler på læserrespons i form af publicerede anmeldelser. Disse anmeldelser præsenteres i forbindelse med en specifik bogtitel. Når man klikker ind på bogen, ser man både antallet af stjerner og bogens samlede anmeldelser. Materialet som undersøges nedenfor er altså publiceret digitalt og tilgængeligt for læsning og videre undersøgelse for alle, som har tegnet et abonnement på Storytel. Når det gælder studier af digitale miljøer, er det vigtigt at påpege, at det af og til er svært at få informeret samtykke 
af deltagerne (Svenningsson Elm, 72.). Når det gælder de anmeldelser, som findes publicerede inden for rammerne af Storytels app, er det muligt at betragte dette miljø som en 'semi-offentlighed', som ifølge Svenningson Elm kan betragtes som et sted, som det er muligt at få adgang til for de fleste, men som kræver registrering og medlemsskab (ibid. 75). Af disse grunde har jeg valgt at anonymisere anmelderne, titlerne på de skønlitterære værker samt forfatternavnene. Det gør jeg også, fordi jeg ikke er interesseret $\mathrm{i}$ at undersøge relationen mellem et bestemt skønlitterært værk i lydbogsform og en specifik læser, men først og fremmest ønsker at indfange de mere generelle temaer, som kendetegner måden, hvorpå lydbogslæsere på forskellig vis diskuterer deres læseoplevelser med andre.

Ved at analysere et udvalg af anmeldelserne, som er publiceret under "Populære titler lige nu!", kan nedenstående analyse altså betragtes som et øjebliksbillede af, hvordan lydbogslæsere diskuterer populære bøger i en bestemt periode. I denne sammenhæng er det vigtigt at påpege, at udvalget er baseret på den svenske version af Storytel samt på anmeldelser, som er skrevet på svensk; det er altså fuldt ud muligt, at denne type af bruger-genereret indhold på appen ser anderledes ud i andre versioner af appen og i andre lande, hvor den er tilgængelig.

Der er flere ligheder i mine unders $\varnothing$ gelser af, hvordan lydbogslæserne på Storytel diskuterer deres skønlitterære fortolkninger og andre studier, som har unders $\varnothing \mathrm{gt}$ kommunikationen blandt læsere i online fællesskaber. ${ }^{\mathrm{I4}}$ En sådan lighed er, at flere af anmeldelserne fremhæver de forskellige følelser, som værket vækker hos læseren. Ord som "elsker" forekommer for eksempel ofte, når anmelderne beskriver, hvilke følelser et bestemt litterært værk genererer. Denne følelsesfuldhed, eller affektive læseform, om man vil, udtrykkes både i ord og ved hjælp af visuelle symboler som specifikt forbindes med digitale miljøer, som for eksempel emojis eller smileys. En anden lighed i forhold til, hvordan læsere generelt diskuterer litteratur i digitale miljøer er, at anmeldelsen i sig selv anvendes som en direkte kommunikationskanal til forfatteren (ibid.). Dette viser, hvordan lydbogslæseren kan placeres i forhold til en generel udvikling, hvor det digitale medielandskab har medført forandringer for, hvordan forfatteren kan kommunikere med sine læsere, og hvor kontakten med læserne er blevet en central del af den moderne forfatterrolle (jf. Baverstock). Det er således almindeligt, at lydbogslæsere i deres anmeldelser understreger deres forhold til en bestemt forfatters værk eller et bestemt forfatterskab ved at tiltale forfatteren direkte i deres respons. Denne tendens kan illustreres gennem følgende citat: "Vidunderlige XX. Hver gang jeg har læst en af dine bøger færdig, føler jeg det som om, noget forsvinder."

Samtidig er der visse aspekter i anmeldelserne, som forholder sig mere specifikt til netop lydbogens form og format, idet for eksempel oplæserens betydning og rolle påpeges. I kombination med ovenfor nævnte tendens til en direkte og følelsesladet forfatterappel får det eksempelvis følgende udtryk: "Jeg elsker dine bøger og synes, at oplæseren er fantastisk.” Det relationelle aspekt kommer også til udtryk i form af, at læserne giver udtryk for et forhold til litterære værker, som indgår i en serie af flere bøger, hvor tidligere læseoplevelser af samme forfattere fremhæves; som for eksempel i det følgende citat: "Lige så god som de andre bøger. Nu vil jeg høre fortsættelsen...." eller som her: "Så god; elsker denne serie man vil bare fortsætte 
med den næste [hjerte-emoji].” I denne sammenhæng bliver serie-formatet altså interessant. I takt med at lydbogstjenesterne er vokset frem, har de netop satset specifikt på litterære serier, som produceres som original-indhold; det vil sige, at de udelukkende er tilgængelige på en bestemt streamingtjeneste (jf. Pennlert \& Linkis 2020). Det er også værd at bemærke, at flere læsere giver udtryk for et ønske om, at næste bog i serien skal komme hurtigere. Dermed fungerer anmeldelserne også som en måde for læserne at give udtryk for ønsker eller ligefrem komme med specifikke anmodninger til forfatteren eller forlaget. Særligt i forhold til serieformatet udtrykker anmelderne ofte, at de ønsker, at næste bog i serien skal komme 'hurtigere'. En anmelder påpeger følgende: "Ærgerligt at man skal vente på næste bog." At det at vente på fortsættelsen opleves som mindre positivt er også noget, som andre anmeldere påpeger, hvilket medfører, at læserne udvikler en form for fællesskab og besvarer hinandens indlæg. Dialogen mellem læsere kan eksemplificeres ved følgende udveksling af replikker:

46 "Elsker denne serie! Ville ønske at bøgerne kom hurtigere!"

"Vil også ønske at bøgerne kom hurtigere, er så god"

"Vil også ønske at bøgerne kom hurtigere."

Samtidig illustrerer citaterne lydbogsproducentens dilemma: valget mellem at gøre samtlige værker i en serie tilgængelige med det samme eller i stedet publicere litterære serier i intervaller, for derved at fastholde læserens interesse og fremme loyaliteten mod selve tjenesten. ${ }^{15}$

I forhold til lydbogens mediespecifikke egenskaber diskuterer læserne også af og til, hvad der er for en stemning, oplæsningen skaber hos dem. Når titlerne på listen anmeldes, betones den stemning, som værket formidler, idet det konstateres at bogen er "dejlig", "charmerende" eller "underholdende".

Det er dog ikke bare gennem Storytels egen app, at læsere mødes for at diskutere lydbogen. Også på andre digitale mødesteder som Facebook mødes lydbogslæsere og diskuterer og publicerer deres domme over litterære værker. Facebookgruppen "Snacka om ljudböcker" har knap 16.000 medlemmer. Gruppen administreres af et antal aktive Facebook-brugere, som også arbejder i forskellige funktioner på Storytel. Disse personer har rollen som redaktører, sådan som man også ser det i andre digitale fællesskaber. ${ }^{16}$ De har først og fremmest ansvar for at holde øje med, at gruppens indlæg holder sig inden for rammerne af de fastlagte sociale retningslinjer, og de forbeholder sig retten til at fjerne indlæg som ikke bidrager til en "konstruktiv eller god stemning i gruppen. ${ }^{{ }^{\prime} 7}$ I gruppen kommer læsere med bogtips og anmeldelser og diskuterer spørgsmål, som vedrører lydbøger. Forfattere til lydbøger er også velkomne til at deltage i diskussionen - hvad nogle af dem faktisk af og til gør. Dette viser, hvordan det digitale medielandskab påvirker relationerne mellem forfattere og læsere. ${ }^{18}$ Diskussionerne i Facebook-gruppen ligner dem, som optræder i appen, idet lydbogsoplevelsen oftest beskrives på følelsesmæssig vis, ved at læserne på forskellig vis betoner deres forhold til lydbogen som format, til oplæseren eller til forfatteren. I Facebook-gruppen findes der også indlæg, som mere tydeligt fremstår som direkte opfordringer, hvor læseren for eksempel kan efterlyse andre 
læseres synspunkter for at danne sig et indtryk af en bestemt lydbog, eller for at sammenligne og diskutere deres læseoplevelse med andre. Dette sker også gennem spørgsmål som, "hvad syntes I om XX? - jeg elskede den." Denne type af spørgsmål viser, hvordan lydbogslæsere går i dialog med andre og aktivt søger mod sociale sammenhænge, hvor der findes andre læsere. Svarene fra andre læsere understreger også koblingen mellem bogens litterære kvaliteter og den følelse, som bogen skabte, som eksemplificeret i følgende svar: "Vidunderligt, føles tomt bagefter" eller "lige nu føles det tomt. Jeg er nok lidt forelsket i den serie."

Læsernes forskellige former for respons og indbyrdes kommunikation, som denne kommer til udtryk inden for rammerne af Storytels app eller på Facebook, viser, hvordan de også har en tendens til at efterlade sig meget kortfattede bedømmelser, hvilket generelt kendetegner læsere på internettet ifølge Petra Söderlund. Söderlund peger på, at disse læsere "ikke altid" er så "verbalt udførlige i deres bedømmelser, snarere tværtimod" (Söderlund 2012, 196).

\section{Konklusion og diskussion}

Ud fra ovenfor nævnte eksempler kan man konkludere, at lydbogslæsere på flere forskellige måder præsenterer deres litterære oplevelse som en kropslig og følelsesmæssig tilstand. På denne måde kan studier af lydbogsoplevelser forbindes med, hvordan læseren, i tråd med Felski, uanset formatet forholder sig til litterære værker gennem følelsesmæssig tilknytning. Undersøgelser af lydbogslæseren gør det således muligt, dels at sige noget specifikt om, hvordan en samtidig populær form for lydbogsbrug fungerer, dels på længere sigt at bidrage til læseforskningen generelt. Det affektive perspektiv kommer til udtryk, både i forbindelse med selve læseprocessen, den litterære teksts form og fortællestruktur (serieformatet), og gennem læsernes direkte kommunikation med forfatteren. Endelig kommer den til udtryk, idet læserne giver udtryk for en følelse af savn eller tab, når læseoplevelsen er slut. Denne høje grad af følelsesmæssighed i læserresponsen viser, hvordan lydbogslæseren kan sammenlignes med lystlæseren i den digitale kultur, sådan som denne defineres af Petra Söderlund. Söderlund diskuterer lystlæseren på følgende måde:

4 Læseoplevelser er meget private og personlige for lystlæserne. Læseoplevelsen forbindes i stor udstrækning med identifikation og genkendelse (...). I internetfora diskuterede man bøger og litteratur med livet som indsats, dvs. deltagerne tolkede og oplevede litteratur i lyset af deres egne tilværelser og private oplevelser og følelser. (Söderlund 2012, 197)

Så hvor befinder lydbogslæseren sig, altså i forhold til læsning som en individuel eller social praksis? For at vende tilbage til de indledende citater af Bloom og Rodero, så er det ved hjælp af ovenstående eksempler muligt at nuancere forestillingerne om læsning eller lytning som primært individuelle aktiviteter. Det sociale engagement, som lydbogslæserne giver udtryk for i deres anmeldelser, kan også ses som et resultat af, at vi befinder os i en samtidig bogkultur, som fremmer kollektive dimensioner, og hvor mennesker gerne vil mødes omkring et specifikt litterært værk, 
uanset om deres primære tilgang til dette værk er at lytte til en lydbog eller læsning af en trykt tekst. Denne sociale opførsel hos læsere er ikke noget nyt i et historisk perspektiv, men den kan i vores digitale samtid, hvor læseren selv publicerer og kommunikerer digitalt, få tydeligere konturer, bl.a. idet læseren efterlader sig spor, som forskeren kan følge.

Sandsynligvis kommer den teknologiske udvikling og de sociale grænseflader også i fremtiden til at være afgørende for, hvordan mennesker kommer i kontakt med litterære tekster, ligesom de kommer til at påvirke muligheder for interaktion mellem tekst og læsere eller læsere imellem. Selvom litteraturlæsningen måske ikke per se, i tråd med Bloom, kan siges at handle om at forandre eller forbedre andre menneskers liv, så er det klart, at lydbogen og litteraturforbrug for lydbogslæseren på forskellig vis er tæt forbundet med det pågående levede, aktive og sociale liv.

\section{Oversat fra svensk af Sara Tanderup Linkis}

\section{Noter}

I Se for eksempel Steiner 2012.

2 Jf. for eksempel Götselius, T. 2010).

3 Se for eksempel Baron 2009.

4 Se Söderlund 2008.

5 Svedjedal (red.) 2012. Jf. gerne Svedjedal 1999.

6 Jf. Have \& Stougaard Pedersen 2016.

7 Se f.eks. https://kulturbloggen.com/?p=127288).

8 Se Koepnick 2013, 232-237. Se også Linkis 2020.

9 Se Hanner, O'Connor og Wikberg 2019, 42.

Io Se f.eks. Pennlert 2018; Söderlund 2012.

II Se f.eks. Prytz 2016.

I2 Jf. Pennlert 2018.

I3 Jf. Birke \& Christe 2013.

I4 Jf. for eksempel Pennlert 2018.

I5 Se f.eks. https://digital.di.se/artikel/bokforlagen-rasar-mot-storytel-en-konstant-nedgang.

I6 Jf. Pennlert 2018.

I7 Jf. https://www.facebook.com/groups/ljudbocker/about/.

I8 Jf. f.eks. Wikström, P. "Boken, berättelsen och pengarna i den digitala tidsåldern.” 271-281.

\section{Litteratur}

Baron, Dennis (2009): A Better Pencil: Readers, Writers and the Digital Revolution. New York: Oxford University Press.

Baron, S. Naomi (2015): Words on Screen: the Fate of Reading in a Digital World. New York: Oxford University Press.

Baverstock, Alison (2011): The Naked Author - A Guide to Self-Publishing. London: Bloomsbury. Birke, Dorothee \& Birke, Christ (2013): "Paratext and the Digitized Narrative: Mapping the Field", i Narrative, vol. 21, nr. 1. s. 65-87. 
Bloom, Harold (2000): How to Read and Why. New York: Scribner.

Bolter, Jay David, \& Grusin, Richard (1999): Remediation: Understanding Social Media. Cambridge Mass: MIT Press.

Bull, Michael (2007): Sound Moves. iPod Culture and Urban Experience. New York: Routledge.

Carlsson, Sven (2016): "Bokförlagen rasar mot Storytel." DIGITAL, 26. august 2016. https://digital. di.se/artikel/bokforlagen-rasar-mot-storytel-en-konstant-nedgang.

Castells, Manuel (2001): The Internet Galaxy: Reflections on the Internet, Business, and Society. Oxford: Oxford University Press.

Cordón García, José-Antonio, Alonso Arévalo, Julio, Goméz Díaz, Raquel, \& Linder, Daniel. (red.) (2013): Social Reading: Platforms, Applications, Clouds and Tags. Chandos Publishing.

Drucker, Johanna (2013): "Performative Materiality and Theoretical Approaches to Interface". I Digital Humanities Quarterly. Volume 7, nr 1.

Fish, Stanley (1980): Is There a Reader in This Class? The Authority of Interpretive Communities. Cambridge Mass: Harvard University Press.

Felski, Rita (2008): Uses of Literature. Malden Mass.: Blackwell Pub.

Fuller, Danielle \& Rheberg Sedo, De Nel (2013): Reading Beyond the Book: The Social Practices of Contemporary Literary Culture. New York: Routledge.

Götselius, Tomas (2010): Skrift och subjekt i Nordeuropa omkring 1500. Göteborg: Glänta.

Hanner, Hedda, O'Connor, Alice, Wikberg, Erik, (2019): “Ljudboken: Hur den digitala logiken påverkar marknaden, konsumtionen och framtiden". Stockholm: Svenska Bokhandlareföreingen och Svenska förläggareföreningen.

Have, Iben \& Stougaard Pedersen, Birgitte (2016): Digital Audiobooks: New Media, Users and Experiences, New York: Routledge.

Hayles. N. Katherine (2008): Electronic Literature - New Horizons for the Literary. Notre Dame Ind: University of Notre Dame.

Hayles, N. Katherine (2012): How We Think - Digital Media and Contemporary Technogenesis. Chicago og London: University of Chicago Press.

Jenkins, Henry (2006): Convergence Culture: Where Old and New Media Collide. New York: New York University Press.

Koepnick, Lutz (2013): "Reading on the Move.” PMLA, vol. 128, nr. 1: 232-237.

Linkis, Sara Tanderup (2020): "Læse/steder: Mobil læsning og stedets betydning i Storytels bornaudio fortællinger." I Julia Pennlert og Lars Ilshammar (red): Från Stringberg til Storytel: Korsskoplingar mellan litteratur och ljud. Daidalos (under udgivelse).

Long, Elizabeth (1993): “Textual Interpretation as Collective action”. I Jonathan Boyarin (red): The Ethnography of Reading, Berkley: Univ. of California Press, s. 180-212.

Malvik, Anders Skare (2009): "Grensesnittens estetik - en begreppsanalytisk tilnaermning til samtidsestetikke och dens medieparadigme" i Tidskrift för litteraturvetenskap, vol. 39 nr. 3-4.

Malvik, Anders Skare (2014): Grensesnittets estetik. Trondheim: Norges teknisk-naturvitenskapelige universitet, Det humanistiske fakultet, Institutt for historiske studier.

Murray, Simone (2018): The Digital Literary Sphere: Reading, Writing and Selling Books in the Internet Era. Baltimore: John Hopkins University Press.

Orfanella, Lou (1998): "Radio: The Intimate Medium", i The English Journal, vol. 87, nr. 1, s. 53-55. Pennlert, Julia (2018a): Poesi pågår - en studie av poeter.se 2013-2016 (diss.), Umeå Universitet: Institutionen för kultur och medievetenskaper. 
Pennlert, Julia (2018b): "I gränssnittet mellan hand och maskin". I Poesiåret 2018, Litteraturkritisk kalender. Stockholm: Örnen och kråkan.

Pennlert, Julia (2019): "Röster om den kommersiella ljudboken". I Nordenstam, A. \& Palmeus Swärd, S (red.): Digitalt. Svensklärarföreningens årsskrift, 0349-0246. Stockholm: Natur \& Kultur, s. 31-44.

Pennlert, Julia \& Tanderup Linkis, Sara (2020): "Episodic Listening: A Study of the Content and Usage of Born-Audio Narratives". I Journal of Electronic Publishing, (under udgivelse).

Prytz, Øyvind (2016): Literatur i en digital tid. Oslo: Spartacus Academic Press.

Rosenblatt, Louise (1968): Literature as exploration. 5 ed. New York: Modern Language Association of America.

Rubery, Matthew (2016): The Untold Story of the Talking Book. Cambridge Massachusetts: Oxford University Press.

Svedjedal, Johan (red.) (2012): Litteratursociologi: Texter om litteratur och samhälle. Lund: Studentlitteratur.

Svedjedal, Johan (1999): "Bortom bokkedjan: Bokmarknadens funktioner - en ny modell och några exempel", Tidskrift för litteraturvetenskap, nr 3-4, Litteraturen och den nya teknologin.

Svenningsson Elm, Malin (2009): "How Do Various Notions of Privacy Influence Decisions in Qualitative Internet Research?” i Markham, A. \& Baym, N. (red.): Internet Inquiry: Conversations about Method. Los Angeles: Sage Publication.

Söderlund, Petra (2012): "Med livet som insats - Om bokprat på internet". I Ulla Carlsson \& Jenny Johanisson (red.): Läsarnas marknad - Marknadens läsare, Statlig Offentlig Utredning 2012:10, Stockholm.

Wikberg, Erik (2018): Boken 2018 - Marknaden, trender och analyser. Stockholm: Svenska Bokhandlareföreningen og Svenska Förläggareföreningen.

Wen, Atlantic, 16.04.2015.

Wikström, Patrik (2012): "Boken, berättelsen och pengarna i den digitala tidsåldern". I Ulla Carlsson \& Jenny Johanisson (red.) Läsarnas marknad - Marknadens läsare, Statlig Offentlig Utredning 2012:10, Stockholm. 